\title{
Mild obstructive sleep apnea does not modulate baroreflex sensitivity in adult patients
}

This article was published in the following Dove Press journal:

Nature and Science of Sleep

25 June 2015

Number of times this article has been viewed

\author{
Henry Blomster ${ }^{1}$ \\ Tomi P Laitinen² \\ Juha EK Hartikainen ${ }^{3,6}$ \\ Tiina M Laitinen ${ }^{2}$ \\ Esko Vanninen ${ }^{2}$ \\ Helena Gylling 4,8 \\ Johanna Sahlman' \\ Jouko Kokkarinen ${ }^{5}$ \\ Jukka Randell ${ }^{5}$ \\ Juha Seppä' \\ Henri Tuomilehto ${ }^{4,7}$ \\ 'Department of Otorhinolaryngology, \\ Institute of Clinical Medicine, \\ ${ }^{2}$ Department of Clinical Physiology \\ and Nuclear Medicine, ${ }^{3}$ Department \\ of Internal Medicine, ${ }^{4}$ Department \\ of Clinical Nutrition, School of \\ Public Health and Clinical Nutrition, \\ University of Eastern Finland, Kuopio, \\ ${ }^{5}$ Department of Respiratory Medicine, \\ ${ }^{6}$ Heart Center, Kuopio University \\ Hospital, ${ }^{7}$ Oivauni Sleep Clinic, \\ Kuopio, ${ }^{8}$ Department of Medicine, \\ Division of Internal Medicine, \\ University of Helsinki, Helsinki, \\ Finland
}

Correspondence: Henry Blomster Department of Otorhinolaryngology, Kuopio University Hospital, PO Box 1777 , FIN-702 I I Kuopio, Finland

Tel $+358 \quad 17 \quad 173270$

Fax +358 I7 I73 244

Email henry.blomster@kuh.fi
Background: Obstructive sleep apnea (OSA) is a chronic and progressive disease. OSA is associated with increased cardiovascular morbidity and mortality, the risk being more frequently encountered with severe degrees of OSA. Increased sympathetic activation and impaired cardiac autonomic control as reflected by depressed baroreceptor reflex sensitivity (BRS) are possible mechanisms involved in the cardiovascular complications of OSA. However, it is not known at what stage of OSA that changes in BRS appear. The aim of this study was to evaluate BRS in patients with mild OSA.

Methods: The study population consisted of 81 overweight patients with mild OSA and 46 body weight-matched non-OSA subjects. BRS, apnea-hypopnea index, body mass index, and metabolic parameters were assessed. The phenylephrine test was used to measure BRS.

Results: Patients in the OSA group were slightly but significantly older than the non-OSA population (50.3 \pm 9.3 years vs $45.7 \pm 11.1$ years, $P=0.02$ ). Body mass index, percentage body fat, blood pressure, fasting glucose, insulin, and lipid levels did not differ between the OSA patients and non-OSA subjects. Absolute BRS values in patients with mild OSA and non-OSA subjects $(9.97 \pm 6.70 \mathrm{~ms} / \mathrm{mmHg}$ vs $10.51 \pm 7.16 \mathrm{~ms} / \mathrm{mmHg}, P=0.67)$ and $\mathrm{BRS}$ values proportional to age-related and sex-related reference values $(91.4 \% \pm 22.7 \%$ vs $92.2 \% \pm 21.8 \%, P=0.84) \mathrm{did}$ not differ from each other. BRS $<50 \%$ of the sex-specific reference value was found in $6 \%$ of patients with mild OSA and in $2 \%$ of non-OSA subjects $(P=0.29)$.

Conclusion: Patients with mild OSA did not show evidence of disturbed BRS in comparison with weight-matched non-OSA controls.

Keywords: obstructive sleep apnea, baroreceptor reflex sensitivity

\section{Introduction}

Obstructive sleep apnea (OSA) is a common sleep disturbance affecting approximately $15 \%-25 \%$ of the population in the working-aged group, and has been found to be an independent risk factor for increased morbidity and mortality. ${ }^{1,2}$ Epidemiological studies have demonstrated a strong link between OSA and cardiovascular diseases such as hypertension, coronary artery disease, atrial fibrillation, stroke, and heart failure. ${ }^{3-5}$ Sympathetic activation has been proposed to be an important factor in the development of these diseases in patients with OSA..$^{6-8}$ It has been postulated that the sympathetic nervous system is activated in response to stimulation of chemoreceptors induced by intermittent asphyxia and hypoxemia as well as the repeated arousals associated with OSA. ${ }^{9-11}$ There are several reports of sympathetic activation in severe OSA, as evidenced by depressed baroreceptor reflex sensitivity (BRS). ${ }^{9,11-20}$ Impaired BRS has been used as a marker of cardiac autonomic dysfunction in many serious diseases, 
including diabetes, chronic heart failure, and coronary artery disease. ${ }^{21-23}$ Depressed BRS has been found to be a significant predictor of arrhythmic death in patients recovering from acute myocardial infarction. . $22,-26^{2}$

OSA is a chronic, insidious disease that can progress independently of other risk factors, including weight gain, 1,27,28 and in particular, the more severe stages of OSA have been linked to an increased risk of cardiovascular morbidity and mortality. However, little is known about the stage of OSA at which the cardiovascular changes appear. It is known that BRS is impaired in the severe stages of OSA, a phenomenon that is independent of obesity. Surprisingly, there have been very few studies examining this issue, and these have been inconclusive, perhaps due to the small sample sizes. Thus, there is no firm evidence, whether BRS may be disturbed already in the early stages of the disease, ie, in mild $\mathrm{OSA}^{12}$ or even in snoring patients without OSA. ${ }^{29-31}$ To address this issue, we conducted the largest study to date determining BRS in patients with mild OSA and body weight-matched non-OSA controls.

\section{Materials and methods Design overview}

The objective of the study was to compare BRS in patients with mild OSA (apnea-hypopnea index [AHI] 5-15/hour) and non-OSA subjects (AHI <5/hour). Our working hypothesis was that BRS would be impaired already in snorers with mild OSA. The patients were given oral and written information about the trial protocol and they provided their written consent. The study protocol was approved by the research ethics committee of the Northern Savo Hospital District and is registered at ClinicalTrials.gov with the identifier NCT00486746.

\section{Patients}

The study was conducted in a single center, ie, Kuopio University Hospital, Finland. All the study subjects were consecutively recruited from the patients referred from the primary health care centers to the outpatient clinics of otorhinolaryngology and respiratory medicine of the Kuopio University Hospital due to a clinical suspicion of sleep-disordered breathing. The recruitment started in October 2004 and ended in December 2006. Patients were assigned to undergo nocturnal cardiorespiratory monitoring. The weight and height were recorded, and the upper airway structure of each patient was reviewed. The inclusion criteria in the OSA group were: working age (18-65 years); body mass index 28-40 kg/m²; and AHI 5-15 events/hour. We excluded patients on any active treatment for OSA, as well as pregnant women and those with chronic kidney, thyroid, or liver disease. The control group consisted of subjects who fulfilled the first two inclusion criteria but did not exhibit any signs of OSA (AHI $<5$ events/hour, Figure 1 ).

\section{Procedures and measurements}

Nocturnal six-channel ambulatory cardiorespiratory monitoring (Embla, Broomfield, CO, USA) at home was conducted in accordance with accepted guidelines for diagnosing OSA. ${ }^{32}$ Nasal flow was assessed by a nasal flow detector, thoracic and abdominal movements were estimated by two piezoelectric belts, oxygen saturation and heart rate were determined by finger pulse oximetry, and body position was monitored. Apnea was defined as a cessation ( $\geq 90 \%)$ of airflow for $\geq 10$ seconds. Hypopnea was defined as a reduction ( $\geq 30 \%$ ) of airflow for $\geq 10$ seconds with oxygen desaturation $\geq 4 \%$. The AHI was defined as the number of apneas and hypopneas per hour, and mild OSA was defined as AHI 5-15 events/hour. ${ }^{33,34}$ Other parameters such as arterial oxygen saturation, time and percentage with arterial oxygen saturation below $90 \%$, and heart rate were assessed. Many routine biochemical parameters were also measured.

\section{Assessment of BRS}

BRS was always evaluated between 10 am and 2 pm using a modification of the method originally described by Smyth et al. ${ }^{48}$ In brief, a bolus injection of phenylephrine $150 \mu \mathrm{g}$ was administered into the antecubital vein to produce a rapid increase in blood pressure and a concomitant reduction in heart rate (increase in R-R interval [RRI]). Beat-to-beat RRIs values were plotted against systolic arterial pressure (SAP) values from the preceding cardiac cycle [ie, RRI $(i)$ $\operatorname{vs} \operatorname{SAP}(i-1)]$ during the period in which blood pressure increased after injection of phenylephrine. A linear regression analysis between $\operatorname{RRI}(i)$ and $\operatorname{SAP}(i-1)$ was performed and can be expressed as follows: $\operatorname{RRI}(i)(\mathrm{ms} / \mathrm{mmHg}$ ), where $i$ is one individual cardiac cycle and $i-1$ is the cardiac beat preceding the $i$ beat. The slope of the regression line $(b)$ represents BRS, $a$ is a constant, and $b$ represents the coefficient derived from the linear regression (first-order equation, Figure 2). Only tests with correlation coefficients of $r>0.80$ or that were statistically significant $(P<0.05)$ were accepted. The phenylephrine test was repeated at 10-minute intervals up to five times in order to obtain three acceptable measurements. The average of the three measurements was used for assessment of BRS. In two cases, we were not able to obtain any acceptable BRS values because of technical problems or ectopic beats. Further, BRS was assessed in proportion to 


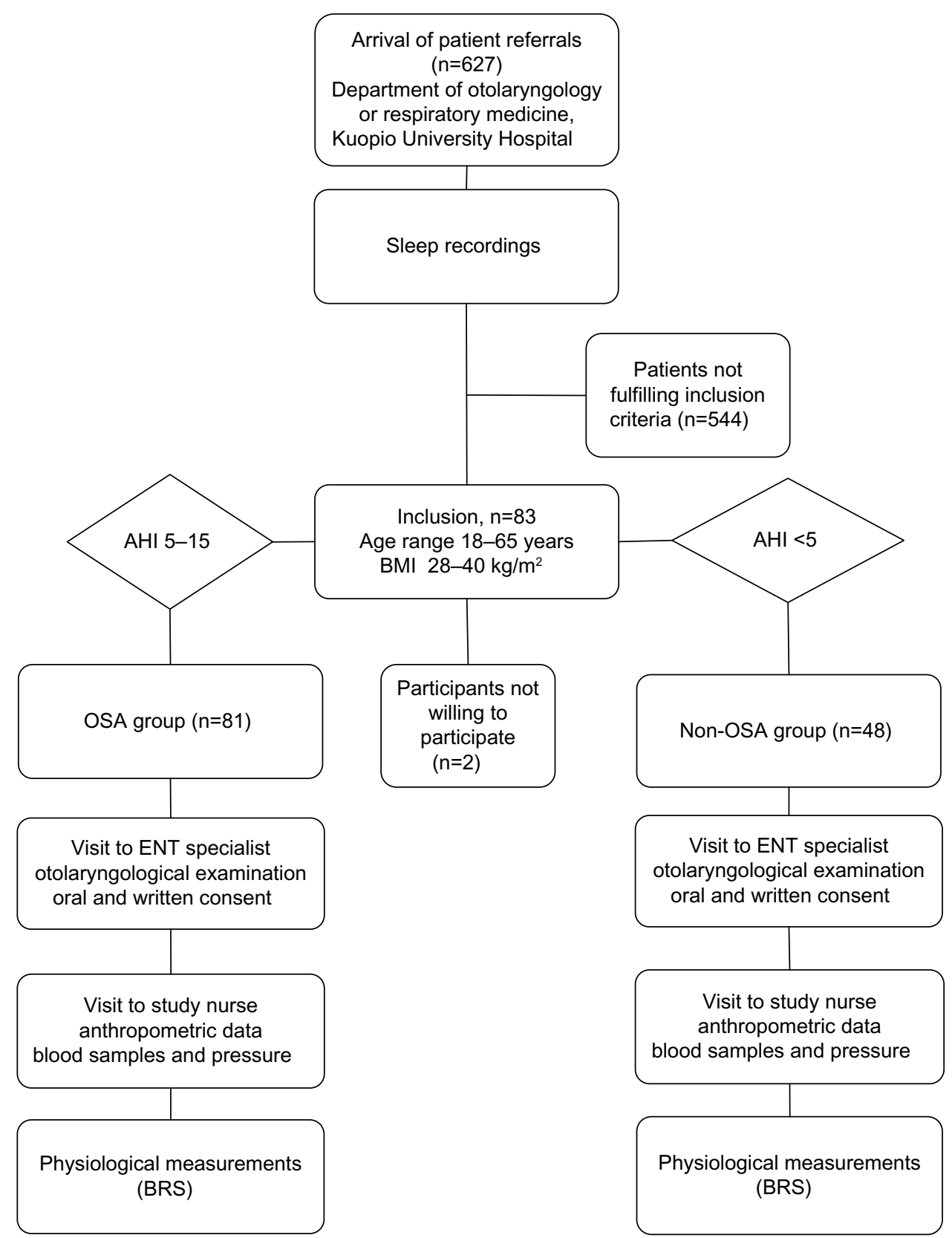

Figure I Study flowchart.

Abbreviations: AHI, apnea-hypopnea index; BMI, body mass index; BRS, baroreceptor reflex sensitivity; ENT, ear, nose, and throat; OSA, obstructive sleep apnea.

age-related and sex-related reference values, with these being calculated as percentages. ${ }^{36}$ The coefficient of variation and correlation coefficient of two measurements performed at 3 -month intervals were $7.4 \%$ and 0.903 , respectively. ${ }^{37}$

\section{Blood pressure and anthropometric measurements}

Blood pressure was measured from the right arm in the sitting position, and recorded three times, after 10 minutes of rest, using a standard sphygmomanometer. The mean value of the measurements was used for analyses. At the study site, a trained nurse measured height, weight, waist circumference, and blood pressure.

\section{Statistical analysis}

Mean values and standard deviations were calculated to describe the characteristics of the two study groups. The Student's $t$-test and Fisher's Exact test were used to assess equality between the groups. The normality of the variables was determined using the Kolmogorov-Smirnov test. For variables with a right skewed distribution, a logarithmic transformation was applied before further analysis. We 

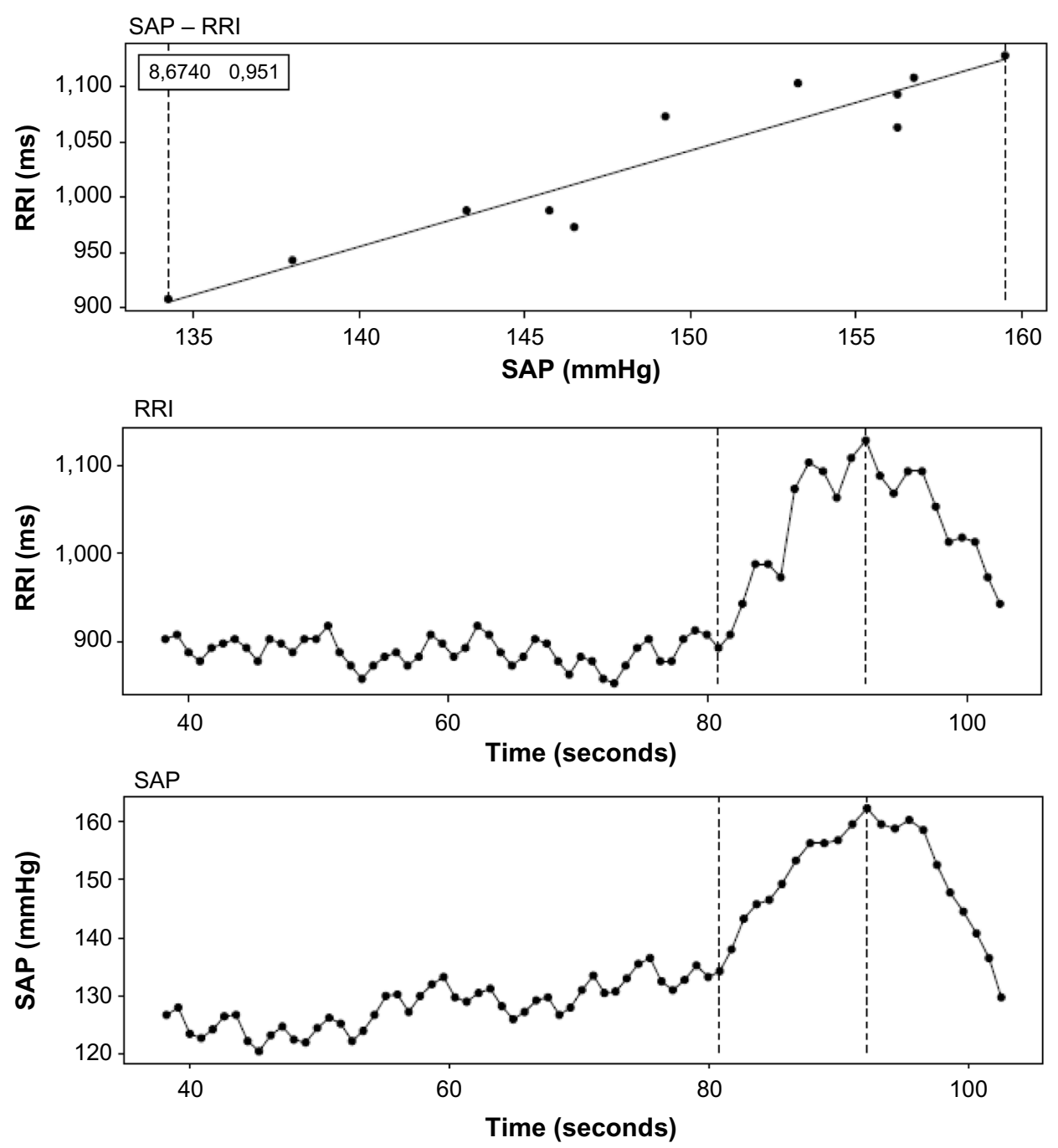

Figure 2 The baroreceptor reflex sensitivity slope method describes the relationship between the change in R-R interval in response to the change of systolic blood pressure of the preceding cardiac cycle. The slope of the regression line corresponds to an arterial baroreflex sensitivity of $8.67 \mathrm{~ms} / \mathrm{mmHg}$ with an acceptable correlation coefficient of 0.95 .

Abbreviations: RRI, R-R interval; SAP, systolic arterial pressure.

report medians and ranges for nonparametric variables in Tables 1 and 2. The differences in risk are reported as odds ratios with $95 \%$ confidence intervals. In the secondary analysis of continuous variables between the OSA and non-OSA groups, the unequal sample size had a power of $80 \%$ to detect a statistical significance of 0.05 (effect size 0.51 ) for a difference between the groups. All characteristics and variables were analyzed with Statistical Package for Social Sciences version 19 software (SPSS Inc., Chicago, IL, USA).

\section{Results}

The body mass index, percentage body fat, blood pressure, fasting glucose, insulin, and lipid levels did not differ between the OSA patients and non-OSA subjects (Table 1). Patients in the OSA group were slightly but significantly older than the non-OSA population ( $50.3 \pm 9.3$ years vs $45.7 \pm 11.1$ years, $P=0.02$ ).

The absolute BRS values $(9.97 \pm 6.70 \mathrm{~ms} / \mathrm{mmHg}$ vs $10.51 \pm 7.16 \mathrm{~ms} / \mathrm{mmHg}, P=0.67)$ as well as $\mathrm{BRS}$ values proportional to age-related and sex-related reference values $(91.4 \% \pm 22.7 \%$ vs $92.2 \% \pm 21.8 \%, P=0.84)$ did not differ between the patients with mild OSA and the nonOSA subjects (Table 2). Furthermore, $6.2 \%$ of participants in the OSA group and $2.1 \%$ in the non-OSA group had BRS $<50 \%$ of the sex-specific reference value $(P=0.29)$. In both groups, men had higher BRS values than women $(11.0 \pm 7.0 \mathrm{~ms} / \mathrm{mmHg}$ vs $7.2 \pm 5.0 \mathrm{~ms} / \mathrm{mmHg}, P=0.02$ and $12.8 \pm 7.8 \mathrm{~ms} / \mathrm{mmHg}$ vs $7.6 \pm 5.3 \mathrm{~ms} / \mathrm{mmHg}, P=0.01$, respectively). Non-OSA subjects had higher fasting serum high-density lipoprotein cholesterol levels $(P<0.05)$, higher average oxygen saturation levels $(P<0.05)$, and a 
Table I Clinical characteristics in mild OSA and non-OSA groups

\begin{tabular}{|c|c|c|c|}
\hline & $\begin{array}{l}\text { Mild OSA } \\
n=8 I \\
(S D)\end{array}$ & $\begin{array}{l}\text { Non-OSA } \\
n=48 \\
\text { (SD) }\end{array}$ & $\begin{array}{l}\text { Significance } \\
P \text {-value }\end{array}$ \\
\hline Age (years) & $50(9)$ & $46(11)$ & 0.02 \\
\hline Sex (male/female) & $60 / 21$ & $27 / 21$ & 0.03 \\
\hline $\begin{array}{l}\text { Time between } \\
\text { sleep and BRS } \\
\text { measurements (days) }\end{array}$ & $72(93)$ & $96(96)$ & 0.17 \\
\hline Body mass index $\left(\mathrm{kg} / \mathrm{m}^{2}\right)$ & $32.5(3.0)$ & $31.7(3.7)$ & 0.17 \\
\hline $\begin{array}{l}\text { Systolic blood } \\
\text { pressure }(\mathrm{mmHg})\end{array}$ & $130(1 \mathrm{I})$ & $132(12)$ & 0.40 \\
\hline $\begin{array}{l}\text { Diastolic blood } \\
\text { pressure }(\mathrm{mmHg})\end{array}$ & 81 (8) & $83(10)$ & 0.72 \\
\hline $\begin{array}{l}\text { Fasting plasma } \\
\text { glucose (mmol/L) }\end{array}$ & $6.16(1.9)$ & $5.89(1.1)$ & 0.37 \\
\hline $\begin{array}{l}\text { Fasting serum } \\
\text { insulin (mU/L) }\end{array}$ & $12.06(5.99)$ & II.58 (5.67) & 0.68 \\
\hline $\begin{array}{l}\text { Fasting serum } \\
\text { cholesterol (mmol/L) }\end{array}$ & $4.70(0.82)$ & $5.00(0.89)$ & 0.06 \\
\hline $\begin{array}{l}\text { Fasting serum HDL } \\
\text { cholesterol (mmol/L) }\end{array}$ & $1.06(0.29)$ & $1.19(0.39)$ & 0.02 \\
\hline $\begin{array}{l}\text { Fasting serum } \\
\text { triglycerides (mmol/L) }\end{array}$ & $1.73(1.11)$ & I.54 (0.89) & 0.32 \\
\hline Hypertension (n) & 34 & 13 & 0.07 \\
\hline $\begin{array}{l}\text { Antihypertensive } \\
\text { medication }(n)\end{array}$ & 38 & 17 & 0.14 \\
\hline Hypercholesterolemia (n) & 26 & 5 & 0.001 \\
\hline $\begin{array}{l}\text { Hypercholesterolemia } \\
\text { medication }(n)\end{array}$ & 26 & 5 & 0.001 \\
\hline Coronary artery disease $(n)$ & 3 & 0 & 0.24 \\
\hline Diabetes $(n)$ & 7 & 2 & 0.28 \\
\hline Diabetes medication $(n)$ & 7 & 1 & 0.13 \\
\hline Current smoker (n) & 21 & II & 0.44 \\
\hline Apnea-hypopnea index & $9.3(3.3)$ & $1.9(1.4)$ & $<0.01$ \\
\hline Mean oxygen saturation (\%) & $94.0(1.4)$ & $94.8(1.7)$ & 0.02 \\
\hline $\begin{array}{l}\text { Time with oxygen } \\
\text { saturation }<90 \% \text { (minutes) }\end{array}$ & $\begin{array}{l}4.6(0.4 \\
304.0)\end{array}$ & $\begin{array}{l}\text { I.8 (0.I, } \\
337.0)\end{array}$ & 0.01 \\
\hline $\begin{array}{l}\text { Percent time with } \\
\text { oxygen saturation }<90 \%\end{array}$ & $\begin{array}{l}1.0(0.1 \\
46.06)\end{array}$ & $\begin{array}{l}0.4(0.1 \\
63.4)\end{array}$ & 0.04 \\
\hline
\end{tabular}

Note: The data are shown as the mean \pm standard deviation, frequency, or median with range.

Abbreviations: BRS, baroreceptor reflex sensitivity; OSA, obstructive sleep apnea; $\mathrm{SD}$, standard deviation; HDL, high-density lipoprotein.

lower AHI $(P<0.001)$ when compared with OSA patients (Table 1). In both groups, BRS was inversely correlated with age, systolic blood pressure, and percentage body fat (Table 3).

\section{Discussion}

The main finding of this study was that BRS as measured by the intravenous phenylephrine test during wakefulness was not impaired in patients with mild OSA when compared with non-OSA subjects. Only $6 \%$ of patients with mild OSA and $2 \%$ of non-OSA subjects displayed signs of impaired BRS.
Table 2 Baroreflex sensitivity in mild OSA and non-OSA groups

\begin{tabular}{llll}
\hline & $\begin{array}{l}\text { Mild OSA } \\
\mathbf{n = 8} \\
(\text { SD) }\end{array}$ & $\begin{array}{l}\text { Non-OSA } \\
\mathbf{n = 4 8} \\
\text { (SD) }\end{array}$ & $\begin{array}{l}\text { Significance } \\
\text { P-value }\end{array}$ \\
\hline $\begin{array}{l}\text { Baroreflex sensitivity } \\
\text { in phenylephrine test } \\
\text { (ms } / \mathrm{mmHg})\end{array}$ & $9.97(6.70)$ & $10.51(7.16)$ & 0.67 \\
$\begin{array}{l}\text { Percentage of reference } \\
\text { value matched for age } \\
\text { and sex }\end{array}$ & $91.4(22.7)$ & $92.2(21.8)$ & 0.84 \\
\hline
\end{tabular}

Notes: The data are shown as the mean \pm standard deviation; the Student's $t$-test for means.

Abbreviations: OSA, obstructive sleep apnea; SD, standard deviation.

There are several studies that have assessed BRS in patients with OSA. Regardless of the techniques used for measurement of BRS, most have demonstrated that severe OSA is associated with a reduction in BRS. Ward et al found that BRS was impaired during wakefulness in subjects with severe OSA which they assessed in three ways, ie, the sequence technique, the spectral transfer function technique, and the alpha index technique. ${ }^{15}$ Similarly, reductions in BRS were detected in patients with moderateto-severe OSA using either the Valsalva technique ${ }^{16}$ or the nitroprusside test. ${ }^{9}$ In addition, there are studies using the sequence method reporting decreased nocturnal BRS in severe OSA. ${ }^{12,13,17}$ Further, it is known that treatment with continuous positive airway pressure improves BRS in OSA patients, suggesting that the impairment of BRS is reversible. ${ }^{17,19}$

Table 3 Univariate correlates of BRS values in mild OSA and non-OSA groups

\begin{tabular}{lll}
\hline & \multicolumn{2}{l}{ BRS $\%$} \\
\cline { 2 - 3 } & Mild OSA & Non-OSA \\
\hline Age & $-0.664^{*}$ & $-0.500^{*}$ \\
Body mass index & -0.122 & -0.027 \\
Percentage body fat & $-0.30 I^{*}$ & $-0.413^{*}$ \\
Systolic blood pressure & $-0.248^{*}$ & $-0.420^{*}$ \\
Diastolic blood pressure & 0.205 & -0.157 \\
Fasting plasma glucose & -0.261 & -0.206 \\
Fasting serum insulin & -0.118 & -0.138 \\
Fasting serum cholesterol & 0.161 & 0.034 \\
Fasting serum HDL cholesterol & 0.134 & -0.189 \\
Fasting serum triglycerides & -0.136 & -0.189 \\
AHI & 0.146 & 0.120 \\
Mean oxygen saturation & 0.297 & -0.215 \\
Time with oxygen saturation $<90 \%$ & -0.394 & 0.279 \\
\hline
\end{tabular}

Notes: Values are shown as Pearson's correlation coefficient and Spearman's coefficient for variables that were not normally distributed; *statistically significant at $P<0.05$.

Abbreviations: AHI, apnea-hypopnea index; BRS, baroreceptor reflex sensitivity; OSA, obstructive sleep apnea; HDL, high-density lipoprotein. 
The effect of mild-to-moderate OSA on BRS is less clear. In our study, assessment of BRS did not reveal any differences between patients with mild OSA and their non-OSA controls. This is in agreement with Ryan et al. ${ }^{12}$ In their study, BRS was lower in patients with severe OSA when compared with patients having mild-to-moderate OSA or non-OSA subjects. However, there was no difference in BRS between the patients with mild-to-moderate OSA and non-OSA subjects. In contrast, our findings and those of Ryan et al, ${ }^{12}$ Noda et al, ${ }^{16}$ and Ward et $a{ }^{15}$ reported reduced values of BRS in patients with mild-to-moderate OSA than those detected in healthy controls. Our study and that reported by Ryan et al used non-OSA snorers as the reference group, whereas the reference groups in the studies by Noda et al and Ward et al consisted of healthy controls, but this is unlikely to account for the differences in the results. There is a report that BRS does not differ in non-OSA snorers and healthy controls during wakefulness. ${ }^{29}$ Interestingly, in the study by Schöbel et al, BRS during the daytime was lower in patients with nocturnal snoring than in healthy non-snorers. ${ }^{31}$ However, BRS was not assessed with the phenylephrine technique, but calculated from spontaneous fluctuations of heart rate and blood pressure using the squared root of the ratio of heart rate variability and systolic blood pressure variability. BRS assessed with the phenylephrine method measures the heart rate response to an increase in blood pressure (vagal activation), whereas BRS assessed from spontaneous blood pressure fluctuations includes heart rate responses to both increased (vagal activation), as well as decreased (vagal withdrawal) blood pressure. Thus, although the phenylephrine method and BRS are based on spontaneous blood pressure oscillations and both assess autonomic reflexes induced by blood pressure change, they cannot be compared with each other.

The underlying mechanism responsible for the reduced BRS is believed to be sympathetic activation caused by nocturnal upper airway collapses, repetitive asphyxia resulting in hypoxia and arousals. ${ }^{38,39}$ In addition, hypoxia over time leading to enhanced chemoreceptor activity may also play a role in the chronic sympathetic activation..$^{40,41}$ Severe OSA is associated with significant cardiovascular morbidity and mortality. ${ }^{2,42}$ Sympathetic activation is considered to be one of the key mechanisms linking OSA to cardiovascular morbidity and mortality. ${ }^{38,41,43}$ However, it is not clear at what stage of OSA the harmful changes in vascular function appear. We have demonstrated that endothelial function is well preserved in patients with mild OSA. ${ }^{44}$ On the other hand, mild OSA is associated with increased activation of the inflammatory system, a symptom that could be normalized by weight loss after successful lifestyle intervention. ${ }^{45,46}$ These findings indicate that the inflammatory system is more susceptible to OSA than cardiovascular regulation.

Decreased BRS is considered to be one of the early markers of autonomic dysfunction in many diseases, including hypertension, ${ }^{22}$ diabetes, ${ }^{21}$ chronic heart failure, ${ }^{23}$ and coronary artery disease. ${ }^{24,47}$ Recent studies have shown that BRS is decreased even in the early asymptomatic stages of coronary artery atherosclerosis, ${ }^{48}$ and impaired BRS predicted cardiovascular death in middle-aged subjects without cardiovascular disease. ${ }^{49}$ BRS measured by the phenylephrine method has been shown to have strong prognostic value in predicting mortality in patients with cardiovascular disease. ${ }^{22,26,50}$ Therefore, this method was applied in our study to assess BRS. While this method has advantages for cardiovascular risk stratification, ${ }^{51,52}$ it has the drawback that, due to the intravenous administration of phenylephrine, it cannot be undertaken when the patient is asleep.

Our results indicate that BRS measured by the phenylephrine test may not be decreased in patients with mild OSA when compared with non-OSA controls. Since OSA has a natural tendency to worsen over time ${ }^{27,53}$ and severe OSA is known to be associated with increased cardiovascular mortality, intervention in the early stages of the disease is essential in order to prevent progression of the disease and development of serious comorbidities.

There are some limitations to this study. The control group consisted of patients referred to hospital due to suspicion of sleep-disordered breathing, ie, snoring. After careful testing, these patients did not show any signs of OSA. In addition, as mentioned earlier, there is a controversy as to whether BRS is sustained in non-OSA snorers, ${ }^{29-31}$ so it is unlikely that using non-OSA snorers would introduce any bias in the interpretation of our results. In addition, the use of weight-matched groups meant that we had metabolic-matched groups, which is of crucial importance when assessing vascular function. The diagnosis of OSA was based on cardiorespiratory recordings from a single night. On the other hand, in routine practice, repeated recordings are extremely demanding, and the findings of single-night recordings have been found to be reliable in most patients. ${ }^{54}$ The patients in the OSA group were slightly older than in the non-OSA group and there were also more males in the OSA group. Since age and sex are important contributors to BRS, in addition to absolute BRS values, we used age-adjusted and sex-adjusted BRS values in these analyses.

In conclusion, BRS was found to be well preserved in patients with mild OSA. This suggests that cardiac autonomic 
dysfunction appears later along the progression to more severe stages of OSA.

\section{Acknowledgments}

The authors cordially acknowledge the members of the Kuopio Sleep Apnea Group, ie, Taina Poutiainen, Matti Pukkila, Tatu Kemppainen, Aki Ikonen, Ritva Vanninen, Heimo Viinamäki, Keijo Peuhkurinen, Kari Punnonen, Kati Venäläinen, Riitta Pahkala, Erkki Soini, and Janne Martikainen. Marjo-Leena Hannila, who assisted with the statistical analysis, is also gratefully acknowledged. The study was funded by the Hospital District of Northern Savo, Kuopio University Hospital. The Organisation for Respiratory Health in Finland (HELI), Kuopio Breathing Association, Antti and Tyyne Soininen Foundation, Väinö and Laina Kivi Foundation, Finnish Anti-Tuberculosis Foundation, and Finnish Research Foundation of Otology also supported the study with grants. The funding sources had no role in the study design; collection, analysis, or interpretation of the data; or writing of the report.

\section{Author contributions}

All authors contributed significantly to the conception and design of the study, acquisition of data, analysis and interpretation of data; drafting and revising of the manuscript; and final approval and agreement of the version to be published.

\section{Disclosure}

The authors report no conflicts of interest in this work.

\section{Reference}

1. Young T, Peppard PE, Gottlieb DJ. Epidemiology of obstructive sleep apnea: A population health perspective. Am J Respir Crit Care Med. 2002;165(9):1217-1239.

2. Punjabi NM, Caffo BS, Goodwin JL, et al. Sleep-disordered breathing and mortality: A prospective cohort study. PLoS Med. 2009;6(8):e1000132.

3. Peppard PE, Young T, Palta M, Skatrud J. Prospective study of the association between sleep-disordered breathing and hypertension. N Engl J Med. 2000;342(19):1378-1384.

4. Nieto FJ, Young TB, Lind BK, et al. Association of sleep-disordered breathing, sleep apnea, and hypertension in a large community-based study sleep heart health study. JAMA. 2000;283(14):1829-1836.

5. Shamsuzzaman AS, Gersh BJ, Somers VK. Obstructive sleep apnea: Implications for cardiac and vascular disease. JAMA. 2003;290(14):1906-1914

6. Somers VK, Dyken ME, Clary MP, Abboud FM. Sympathetic neural mechanisms in obstructive sleep apnea. J Clin Invest. 1995;96(4):1897-1904.

7. Noda A, Okada T, Hayashi H, Yasuma F, Yokota M. 24-hour ambulatory blood pressure variability in obstructive sleep apnea syndrome. Chest. 1993;103(5):1343-1347.

8. Cortelli P, Parchi P, Sforza E, et al. Cardiovascular autonomic dysfunction in normotensive awake subjects with obstructive sleep apnoea syndrome. Clin Auton Res. 1994;4(1-2):57-62.
9. Carlson JT, Hedner JA, Sellgren J, Elam M, Wallin BG. Depressed baroreflex sensitivity in patients with obstructive sleep apnea. Am J Respir Crit Care Med. 1996;154(5):1490-1496.

10. Sforza E, Parchi P, Contin M, Cortelli P, Lugaresi E. Do autonomic cardiovascular reflexes predict the nocturnal rise in blood pressure in obstructive sleep apnea syndrome? Blood Press. 1994;3(5): 295-302.

11. Ziegler MG, Nelesen RA, Mills PJ, et al. The effect of hypoxia on baroreflexes and pressor sensitivity in sleep apnea and hypertension. Sleep. 1995;18(10):859-865.

12. Ryan S, Ward S, Heneghan C, McNicholas WT. Predictors of decreased spontaneous baroreflex sensitivity in obstructive sleep apnea syndrome. Chest. 2007;131(4):1100-1107.

13. Parati G, Di Rienzo M, Bonsignore MR, et al. Autonomic cardiac regulation in obstructive sleep apnea syndrome: Evidence from spontaneous baroreflex analysis during sleep. $J$ Hypertens. 1997;15(12 Pt 2): $1621-1626$.

14. Cooper VL, Elliott MW, Pearson SB, Taylor CM, Mohammed MM, Hainsworth R. Daytime variability of baroreflex function in patients with obstructive sleep apnoea: Implications for hypertension. Exp Physiol. 2007;92(2):391-398.

15. Ward S, Ryan S, Mc Nicholas WT, Heneghan C. Comparison of baroreflex sensitivity measures for assessing subjects with obstructive sleep apnea. Conf Proc IEEE Eng Med Biol Soc. 2006;1:3572-3575.

16. Noda A, Nakata S, Koike Y, et al. Continuous positive airway pressure improves daytime baroreflex sensitivity and nitric oxide production in patients with moderate to severe obstructive sleep apnea syndrome. Hypertens Res. 2007;30(8):669-676.

17. Bonsignore MR, Parati G, Insalaco G, et al. Baroreflex control of heart rate during sleep in severe obstructive sleep apnoea: Effects of acute CPAP. Eur Respir J. 2006;27(1):128-135.

18. Bonsignore MR, Parati G, Insalaco G, et al. Continuous positive airway pressure treatment improves baroreflex control of heart rate during sleep in severe obstructive sleep apnea syndrome. Am J Respir Crit Care Med. 2002;166(3):279-286.

19. Kohler M, Pepperell JC, Casadei B, et al. CPAP and measures of cardiovascular risk in males with OSAS. Eur Respir J. 2008;32(6):1488-1496.

20. Siarnik P, Carnicka Z, Krizova L, et al. Predictors of impaired endothelial function in obstructive sleep apnea syndrome. Neuro Endocrinol Lett. 2014;35(2):142-148.

21. Frattola A, Parati G, Gamba P, et al. Time and frequency domain estimates of spontaneous baroreflex sensitivity provide early detection of autonomic dysfunction in diabetes mellitus. Diabetologia. 1997;40(12):1470-1475.

22. La Rovere MT, Bigger JT,Jr, Marcus FI, Mortara A, Schwartz PJ. Baroreflex sensitivity and heart-rate variability in prediction of total cardiac mortality after myocardial infarction. ATRAMI (autonomic tone and reflexes after myocardial infarction) investigators. Lancet. 1998;351(9101):478-484.

23. Mortara A, La Rovere MT, Pinna GD, et al. Arterial baroreflex modulation of heart rate in chronic heart failure: Clinical and hemodynamic correlates and prognostic implications. Circulation. 1997;96(10):3450-3458.

24. La Rovere MT, Pinna GD, Hohnloser SH, et al. Baroreflex sensitivity and heart rate variability in the identification of patients at risk for lifethreatening arrhythmias: Implications for clinical trials. Circulation. 2001;103(16):2072-2077.

25. La Rovere MT, Schwartz PJ. Baroreflex sensitivity as a cardiac and arrhythmia mortality risk stratifier. Pacing Clin Electrophysiol. 1997;20(10 Pt 2):2602-2613.

26. Farrell TG, Odemuyiwa O, Bashir Y, et al. Prognostic value of baroreflex sensitivity testing after acute myocardial infarction. $\mathrm{Br}$ Heart $\mathrm{J}$. 1992;67(2):129-137.

27. Pendlebury ST, Pepin JL, Veale D, Levy P. Natural evolution of moderate sleep apnoea syndrome: Significant progression over a mean of 17 months. Thorax. 1997;52(10):872-878. 
28. Lindberg E, Elmasry A, Gislason T, et al. Evolution of sleep apnea syndrome in sleepy snorers: A population-based prospective study. Am J Respir Crit Care Med. 1999;159(6):2024-2027.

29. Gates GJ, Mateika SE, Basner RC, Mateika JH. Baroreflex sensitivity in nonapneic snorers and control subjects before and after nasal continuous positive airway pressure. Chest. 2004;126(3):801-807.

30. Mateika JH, Kavey NB, Mitru G. Spontaneous baroreflex analysis in non-apneic snoring individuals during NREM sleep. Sleep. 1999;22(4):461-468.

31. Schobel C, Fietze I, Glos M, et al. Nocturnal snoring decreases daytime baroreceptor sensitivity. Respir Med. 2014;108(7):1049-1055.

32. Sleep-related breathing disorders in adults: Recommendations for syndrome definition and measurement techniques in clinical research the report of an american academy of sleep medicine task force. Sleep. 1999;22(5):667-689.

33. Iber C, Ancoli-Israel S, Chesson A, Quan S. For the american academy of sleep medicine. westchester, ill: American academy of sleep medicine; 2007. the AASM manual for the scoring of sleep and associated events: Rules, terminology and technical specifications. 2007.

34. Collop NA, Anderson WM, Boehlecke B, et al. Clinical guidelines for the use of unattended portable monitors in the diagnosis of obstructive sleep apnea in adult patients portable monitoring task force of the american academy of sleep medicine. J Clin Sleep Med. 2007;3(7):737-747.

35. Smyth HS, Sleight P, Pickering GW. Reflex regulation of arterial pressure during sleep in man. A quantitative method of assessing baroreflex sensitivity. Circ Res. 1969;24(1):109-121.

36. Laitinen T, Hartikainen J, Vanninen E, Niskanen L, Geelen G, Lansimies E. Age and gender dependency of baroreflex sensitivity in healthy subjects. J Appl Physiol (1985). 1998;84(2):576-583.

37. Hartikainen J, Fyhrquist F, Tahvanainen K, Lansimies E, Pyorala K. Baroreflex sensitivity and neurohormonal activation in patients with acute myocardial infarction. Br Heart J. 1995;74(1):21-26.

38. Narkiewicz K, van de Borne PJ, Montano N, Dyken ME, Phillips BG, Somers VK. Contribution of tonic chemoreflex activation to sympathetic activity and blood pressure in patients with obstructive sleep apnea. Circulation. 1998;97(10):943-945.

39. Somers VK, White DP, Amin R, et al. Sleep apnea and cardiovascular disease: An american heart Association/american college of cardiology foundation scientific statement from the american heart association council for high blood pressure research professional education committee, council on clinical cardiology, stroke council, and council on cardiovascular nursing in collaboration with the national heart, lung, and blood institute national center on sleep disorders research (national institutes of health). Circulation. 2008;118(10):1080-1111.

40. Greenberg HE, Sica A, Batson D, Scharf SM. Chronic intermittent hypoxia increases sympathetic responsiveness to hypoxia and hypercapnia. J Appl Physiol (1985). 1999;86(1):298-305.

41. Imadojemu VA, Mawji Z, Kunselman A, Gray KS, Hogeman CS, Leuenberger UA. Sympathetic chemoreflex responses in obstructive sleep apnea and effects of continuous positive airway pressure therapy. Chest. 2007;131(5):1406-1413.
42. Muraja-Murro A, Eskola K, Kolari T, et al. Mortality in middleaged men with obstructive sleep apnea in finland. Sleep Breath. 2013;17(3):1047-1053.

43. Narkiewicz K, van de Borne PJ, Pesek CA, Dyken ME, Montano N, Somers VK. Selective potentiation of peripheral chemoreflex sensitivity in obstructive sleep apnea. Circulation. 1999;99(9):1183-1189.

44. Blomster H, Laitinen T, Lyyra-Laitinen T, et al. Endothelial function is well preserved in obese patients with mild obstructive sleep apnea. Sleep Breath. 2014;18(1):177-186.

45. Sahlman J, Miettinen K, Peuhkurinen K, et al. The activation of the inflammatory cytokines in overweight patients with mild obstructive sleep apnoea. J Sleep Res. 2010;19(2):341-348.

46. Tuomilehto H, Gylling H, Peltonen M, et al. Sustained improvement in mild obstructive sleep apnea after a diet- and physical activity-based lifestyle intervention: Postinterventional follow-up. Am J Clin Nutr. 2010;92(4):688-696.

47. Hartikainen J, Mantysaari M, Mussalo H, Tahvanainen K, Lansimies E, Pyorala K. Good exercise capacity at hospital discharge predicts recovery of baroreflex sensitivity after myocardial infarction. Eur Heart J. 1995;16(11):1520-1525.

48. Simula S, Laitinen T, Vanninen E, et al. Baroreflex sensitivity in asymptomatic coronary atherosclerosis. Clin Physiol Funct Imaging. 2013;33(1):70-74.

49. Kiviniemi AM, Tulppo MP, Hautala AJ, et al. Prognostic significance of impaired baroreflex sensitivity assessed from phase IV of the valsalva maneuver in a population-based sample of middle-aged subjects. $\mathrm{Am}$ J Cardiol. 2014;114(4):571-576.

50. Farrell TG, Paul V, Cripps TR, et al. Baroreflex sensitivity and electrophysiological correlates in patients after acute myocardial infarction. Circulation. 1991;83(3):945-952.

51. Goldberger JJ, Cain ME, Hohnloser SH, et al. American heart Association/American college of cardiology Foundation/Heart rhythm society scientific statement on noninvasive risk stratification techniques for identifying patients at risk for sudden cardiac death. A scientific statement from the american heart association council on clinical cardiology committee on electrocardiography and arrhythmias and council on epidemiology and prevention. J Am Coll Cardiol. 2008;52(14): 1179-1199.

52. La Rovere MT, Maestri R, Robbi E, et al. Comparison of the prognostic values of invasive and noninvasive assessments of baroreflex sensitivity in heart failure. J Hypertens. 2011;29(8):1546-1552.

53. Berger G, Berger R, Oksenberg A. Progression of snoring and obstructive sleep apnoea: The role of increasing weight and time. Eur Respir J. 2009;33(2):338-345.

54. Fietze I, Dingli K, Diefenbach K, et al. Night-to-night variation of the oxygen desaturation index in sleep apnoea syndrome. Eur Respir J. 2004;24(6):987-993.
Nature and Science of Sleep

\section{Publish your work in this journal}

Nature and Science of Sleep is an international, peer-reviewed, open access journal covering all aspects of sleep science and sleep medicine, including the neurophysiology and functions of sleep, the genetics of sleep, sleep and society, biological rhythms, dreaming, sleep disorders and therapy, and strategies to optimize healthy sleep. The journal welcomes

\section{Dovepress}

original research, clinical \& epidemiological studies, reviews \& evaluations, case reports and extended reports. The manuscript management system is completely online and includes a very quick and fair peerreview system, which is all easy to use. Visit http://www.dovepress.com/ testimonials.php to read real quotes from published authors. 